Volume 1 Issue 1

June 2016

\title{
Introducing the Irish Journal of Paramedicine Editorial Board.
}

Alan M. Batt

Editor, Irish Journal of Paramedicine. editor@irishparamedicine.com

\section{Recommended Citation}

Batt AM. Introducing the Irish Journal of Paramedicine Editorial Board. Irish Journal of Paramedicine. 2016 Jun; 1(1)

This is an Open Access article distributed under the terms of the Creative Commons Attribution-Non-Commercial-ShareAlike 4.0 International (http://creativecommons.org/licenses/by-nc-sa/4.0/), which permits use, distribution, and reproduction in any medium, provided the original work and any attributes thereof are properly cited, are distributed under the same licence, and that the work is not used for commercial purposes.

Follow the Irish Journal of Paramedicine online at www.irishparamedicine.com, on Twitter (@irishjparamed) and on Facebook. 
EDITORIAL

\section{Introducing the Irish Journal of Paramedicine Editorial Board}

Alan M. Batt

Editor, Irish Journal of Paramedicine

Correspondence: Alan M. Batt, 1001 Fanshawe College Blvd, London, ON N5Y5R6, Canada. Email: editor@irishparamedicine.com

Welcome to the first issue of the Irish Journal of Paramedicine (IJP). Our editorial board consists of respected academics, researchers, clinicians and educators from Ireland and abroad who are committed to furthering the cause of paramedicine, and encouraging its future development of professional standing.

\section{Mr. Alan Batt GradCertICP MSc(c) CCP Editor, Irish Journal of Paramedicine}

Alan is an Irish paramedic who previously worked with the National Ambulance Service in Ireland. He has previous experience across Europe, North America and the Middle East as a critical care paramedic, educator, researcher and consultant. He is currently faculty in the Primary Care and Advanced Care Paramedic programs at Fanshawe College, Canada, faculty in several clinical and research programmes at Portland Community College, USA and a Paramedic Educator with the Centre for Paramedic Education and Research, Hamilton Health Sciences in Canada. He is also a Research Paramedic with National Ambulance in the United Arab Emirates, where he leads all research activities within the service. He holds a Certificate in Critical Care Paramedicine and a Graduate Certificate in Intensive Care Paramedic Studies, and is currently finishing an MSc in Critical Care. He has research affiliations with several international research centres related to prehospital care and care of the elderly, and has presented and published research findings internationally.

\section{Dr. William Leggio MS EdD NRP}

\section{Associate Editor, Irish Journal of Paramedicine}

William is clinical faculty and paramedic program coordinator at Creighton University in Omaha, Nebraska. His experiences as a scholarly practitioner includes academic service in the Middle East, publishing in and supporting peer reviewed journals, and serving on a variety of community, university, and professional organization committees. He is passionate about advancing EMS education in the United States, embracing interdisciplinary initiatives in the health sciences, increasing global understanding of EMS, and evidence based decision making in EMS. He has completed an MS in Negotiation and Dispute Resolution and a Doctor of Education (EdD) in Interdisciplinary Leadership from Creighton University, Nebraska, USA.

\section{Mr. Joseph Acker MA PhD(c) EMT-P(cc) MPA}

Joe is a Senior Lecturer in Paramedicine at Charles Sturt University (CSU) in Port Macquarie, NSW, a founding member of International Paramedic, and a Board Member of Paramedics Australasia. Joe has 25-years experience as an urban and rural paramedic, critical care flight paramedic, senior manager, ambulance service executive, researcher and paramedic academic. Joe maintains his clinical practice as an Intensive Care Paramedic with the New South Wales Ambulance Service. Joe has gained international experience working, consulting, and studying prehospital care in Australia, Canada, the United States, China, Abu Dhabi, Dubai, Brunei, and the UK. As a PhD candidate at CSU, Joe is researching remote and industrial paramedic practice in Australasia.

\section{Dr. Malcolm Boyle ADipBus ADipHSc(Amb Off) MICACert BInfoTech GCertAcaPrac MClinEpi PhD FPA}

Mal has been a paramedic for over 30 years with the last 22 years as a Mobile Intensive Care Ambulance (MICA) Paramedic in Victoria, primarily working in rural areas. Mal has been working in academia since 1999. His PhD looked at triage and error detection in prehospital trauma management.

\section{Mr. Eddie Callachan NDip MHSc PhD(c)}

Eddie has been a practicing advanced life support paramedic for 20 years, 15 years of which has been as a flight paramedic. His current position is as deputy chief flight medic for the UAE Armed Forces SAR program which he has held for 13 years. He holds the South African National Diploma in Emergency Care, Postgraduate Certificate and Diploma in Retrieval Medicine and a Master of Health Sciences in Aeromedical Retrieval and Transport from the University of Otago and is currently in his final year of a $\mathrm{PhD}$ in Emergency Medicine. Eddie also serves as a paramedic examiner for the Health Authority in Abu Dhabi licensing committee, and adjunct lecturer for the Bachelor of Emergency Health degree program at Fatima College of Health Sciences in Abu Dhabi

\section{Mr. Marc Colbeck MACP PhD(c) CCP}

Marc was a Critical Care Paramedic in Toronto, Canada who is now a Senior Lecturer and Course Coordinator of the Bachelor of Paramedicine degree at the Australian Catholic University in Brisbane. He spent several years teaching paramedicine in the Middle East, was previously the General Manager of Clinical Governance for South Australia Ambulance Service, and is currently a candidate for a $\mathrm{PhD}$ in Medicine from the University of Adelaide. He holds a Master of Arts in Counseling Psychology. 


\section{Mr. Eoghan Connolly HDipEMT MScEMS AP} Eoghan is an Advanced Paramedic with the National Ambulance Service in Ireland. He holds a Higher Diploma in Emergency Medical Technology and a Master of Science in EMS (Advanced Paramedic). He leads the research and education portfolio for the Irish College of Paramedics.

\section{Mr. Keith Colver MPhil}

Keith is Clinical Governance Manager for the Scottish Ambulance Service, having previously served as Resilience Advisor and Special Operations Response Team Manager. He has previously published on treat and refer guidelines and mass casualty incident preparedness.

\section{Dr. Patrick Cotter RGN RM ANP BSc MSc DNP}

Patrick works as an Advanced Nurse Practitioner in Emergency Nursing in Cork University Hospital, Ireland and was the first graduate of the Doctorate of Nursing Programme in University College Cork. In addition to this, he teaches on several undergraduate and postgraduate nursing programmes in University College Cork.

\section{Associate Professor Fergal Cummins MB BCh BAO BMedSci MSc(DM) DMMD FRCEM FACEM FRCSEd $(\mathrm{A} \& \mathrm{E})$}

Fergal is a Consultant in Emergency Medicine and Retrieval Medicine. He gained his primary medical degree from University College Cork. In addition, he holds an MSc in Disaster Medicine from the Université Libre de Bruxelles (Belgium) and from the Università degli Studi del Piemonte Orientale 'Amedeo Avogadro' (Italy). He has worked as a Consultant in Emergency Medicine and Retrieval Medicine in Europe and Australasia. He holds the academic positions of Associate Professor at Charles Sturt University, NSW, Australia and Senior Clinical Lecturer at the University of Limerick, Ireland. He joined National Ambulance in the UAE in June 2013 where he is responsible for the development and management of all clinical services for the organisation in the United Arab Emirates.

\section{Professor Stephen Cusack MB BCh BAO BSc FRCSI FRCEM}

Stephen is a graduate of University College Dublin. His basic professional training was in Dublin and he undertook his training in Emergency Medicine in Scotland at the Royal Infirmaries of Edinburgh and Glasgow. His interest in Prehospital Emergency Medicine developed when he worked on Edinburgh Royal Infirmary's 'Medic One'. He was appointed as the first, and to date only, Chair of Emergency Medicine in Ireland at University College Cork in 2010. He has sat on the Prehospital Emergency Care Council's Medical Advisory Committee since its inception and continues to try and drive the development on Prehospital Emergency Care in Ireland.

\section{Mr. Mark Dixon MSc AP}

Following 30 years in EMS, Mark is now Course Director for three third level programmes, heading the Paramedic Studies Department based in the Graduate Entry Medical School of the University of Limerick. Each programme contains a heavy research and evidence based practice theme with Mark pushing this new EMS agenda whenever possible. He has presented his prehospital research findings in multiple countries across three continents. His specialist areas of research include supraglottic airway management, high fidelity simulation and spinal immobilisation.

\section{Mr. Ricky Ellis HDipEMT MScLMD AP}

Ricky holds an MSc in Leadership and Healthcare Management Development and is an adjunct faculty member of the Royal College of Surgeons, (Institute of Leadership), where he provides supervision on the Masters programme in Healthcare Management and also provides leadership development coaching on several of RCSI's external leadership programmes. Ricky is a practicing Advanced Paramedic with Dublin Fire Brigade who has a history of educational programme development and was seconded to PHECC on a project which saw him redevelop the national examination framework (NQEMT) for three clinical grades in Ireland. He has also published peer reviewed EMS educational research into e-learning and presented this research at a number of international conferences. He has lectured on personal leadership development to the Irish College of Paramedics and other Irish healthcare practitioners.

\section{Mr. Darren Figgis MScEMS DipIMC(RCSEd) AP}

Darren has been working in the Ambulance Service since 1995. Qualifying as a Paramedic in 1999 he became an Advanced Paramedic in 2008. In 2012 he completed an MSc in Emergency Medical Science (Immediate Care) and holds a Diploma in Immediate Medical Care (RCSEd). He has worked as a pre-hospital care professional in four countries across three continents. Now he is currently assigned to the Emergency Aeromedical Service on behalf of the National Ambulance Service.

\section{Dr. David Fitzpatrick PhD DipIMC(RCSEd)}

David is a Paramedic Clinical Research Specialist employed by the Scottish Ambulance Service and has been attached to the Scottish Government, Chief Scientist Offices' Nursing, Midwifery and Allied Health Professions Research Unit (University of Stirling) for the past 10 years. His position within the Scottish Ambulance Service Clinical Directorate involves undertaking applied research aligned to the services clinical strategy. David's work focuses on improving the quality and safety of pre-hospital emergency and unscheduled care. He completed his $\mathrm{PhD}$ in 2015 whereby he undertook a multiple methods investigation into pre-hospital hypoglycaemic care in Scotland. Several other projects are 
ongoing at present and involve hypoglycaemic care, mental health/psychiatric related emergencies, COPD, pre-hospital and in-hospital handover. David continues to practice clinically as a paramedic within the West Division of the Scottish Ambulance Service.

\section{Mr. Damien Gaumont HDipEMT AP}

Damien is a French born paramedic who has spent over 17 years working on the front line; initially as an occupational first aider at sea, a firefighter and now as an Advanced Paramedic and Flight Paramedic for the National Ambulance Service in Ireland. Damien is now an Assistant Tutor at the Paramedic Studies Department, Graduate Entry Medical School in the University of Limerick. He is also affiliated with the Centre for Prehospital Research in UL, where he has conducted research projects and undertakes Clinical Practice Guideline reviews. He has experience in adapting and teaching courses in French and English, and setting up a community based Public Access Defibrillator Program.

\section{Dr. John Glasheen MB BCh BAO BMedSci BSc MScEMS MRCEM}

John started his prehospital career as an EMT and later as a paramedic in Ireland. He graduated from medical school at University College Cork in 2008, and completed a MSc in Emergency Medical Science (Immediate Care) while working in various critical care posts in Cork and Limerick. He moved to Australia in 2013 to gain further experience in prehospital and retrieval medicine with Sydney HEMS and with Careflight in Queensland. He is currently an Emergency Medicine registrar in Brisbane, and continues to work with Careflight.

\section{Mr. David Halliwell MSc Paramedic}

Dave is a paramedic researcher and developer of immersive education strategies. He has almost 30 years of experience in prehospital care and paramedicine. An Olympic gold commander for sailing, David is currently advising and educating teams throughout the Middle East on mass casualty response and counter terror measures. Dave was the main investigator for the UK arm of the LINC study - Lucas in Cardiac Arrest. $\mathrm{He}$ is a Director at the Academy of Professional Development based near London, and an international lecturer/educator for EMS and disaster relief strategies. He is often found in many of the worlds trouble zones helping to implement education strategies and newer technologies. A former army medic, David joined Dorset Ambulance service in 1989 and progressed from care assistant to head of education for the South Western Ambulance Service Trust.

\section{Mr. Kieran Henry HDipEMT MScEMS AP}

Kieran is an Advanced Paramedic and Supervisor with the National Ambulance Service based on a front line emergency ambulance in Cork City and also completes rotations on the Emergency Aeromedical Service based in Athlone. He has completed an MSc in Emergency Medical Science (Advanced Paramedic) through UCD and has presented his published research on Out of Hospital Cardiac Arrest at conferences in China and Spain. He is actively involved in teaching neonatal and paediatric resuscitation and was a key player in an Irish-Sudanese maternity hospital partnership project. A PHECC registered tutor, his other interests include teamwork development and crew resource management. He is the founder and co-organiser of 'EMS Gathering' an international pre-hospital event held in Ireland.

\section{Dr. Jason Horan MB BCh BAO BMedSci DipMedTox DipIMC(RCSEd) MRCSEd FRCEM}

Jason graduated from University College Dublin in 2002. He embarked on specialist training in Emergency Medicine in Ireland and took up his first Consultant post in 2013. He currently works in Mayo University Hospital. He has been involved with the Graduate Diploma in Emergency Medical Science in UCD since 2008. He holds postgraduate diplomas in medical toxicology and immediate medical care. $\mathrm{He}$ is medical advisor for Mountain Rescue Ireland and is on the WEMSI-International faculty for their Wilderness EMT and Wilderness Physician programmes. $\mathrm{He}$ is also the clinical lead for Mayo ICRR (Irish Community Rapid Response).

\section{Ms. Tania Johnston RN MA PhD(c) EMT-P(cc)}

Dual trained as a paramedic and nurse, Tania has 22 years experience in prehospital care. Her clinical experience includes emergency nursing as well as paramedic practice in rural and urban ambulance services. Tania spent two years teaching in the paramedic program at the Northern Alberta Institute of Technology (NAIT), in Edmonton, Alberta, Canada before transitioning into an educator role with the Shock Trauma Air Rescue Society (STARS) air ambulance retrieval program. She enjoyed working as a critical care flight nurse/paramedic and Medical Base Manager during her $5 \frac{1}{2}$ years with STARS. Upon completing her Master's studies, Tania gained valuable experience working in government in the area of Emergency Medical Services and provincial air ambulance dispatch. Since arriving in Australia in 2010, she has been involved in educating CSU paramedic students and is a lecturer in the Bachelor of Clinical Practice (Paramedicine) at the Port Macquarie, NSW campus. She continues to practice as an emergency nurse and paramedic in New South Wales. Additionally, she enjoys spending time travelling internationally as a cruise ship nurse. Tania is currently studying for her $\mathrm{PhD}$ on the topic of paramedic professionalism.

\section{Dr. Shane Knox HDipEMT MSc PhD AP}

Shane is an Assistant Chief Ambulance Officer and an Advanced Paramedic Educator currently employed as the Education Manager in Ireland's National Ambulance Service College. Shane is also a UK registered Paramedic, a member of the College of Paramedics (UK) and President of the Irish College of Paramedics. The topic of Shane's PhD was 'A 
model of Continuous Professional Development for PreHospital Practitioners in Ireland'. This $\mathrm{PhD}$ represents the first such award in Ireland for a pre-hospital practitioner and the first awarded by an Irish University (University of Limerick, Graduate Entry Medical School) to a member of the paramedic discipline.

\section{Mr. Ciaran McKenna BSc(Hons.) DipECP}

Ciaran trained as a Paramedic in London, completing his BSc Hons in Paramedic Science in 2005. He continued his studies and gained his Emergency Care Practitioner Diploma in 2010. He worked for the London Ambulance Service for 12 years during which time he undertook a number of operational and management roles including working as a Station Officer and Venue Commander at the 2012 London Olympics. In 2011-2012, Ciaran completed a secondment as a Flight Paramedic with London's Air Ambulance. He returned to Northern Ireland in 2013 and is currently employed as the Clinical Service Improvement Lead with the Northern Ireland Ambulance Service. His current role involves the development and implementation of Appropriate Care Pathways.

\section{Dr. Adrian Murphy MB BCh BAO BMedSci DipForensicMed PhD MRCSI}

Adrian graduated from University College Cork (UCC) in 2003 and undertook his higher specialist training in emergency medicine at various hospitals throughout Ireland. Adrian was conferred with a $\mathrm{PhD}$ from University College Dublin in 2015 for research exploring current and future trends in prehospital paediatric pain management. His research has directly facilitated the introduction of intranasal fentanyl for use by advanced paramedics in Ireland for the prehospital treatment of acute severe pain in children. Adrian has completed a Fellowship in Prehospital Emergency Care with London Air Ambulance and is currently a Consultant in Emergency Medicine and Prehospital Emergency Care in Cork, Ireland.

\section{Dr. David Menzies MB BCh BAO BA MD DipMedTox DMMD DipIMC(RCSEd) FRCEM}

David is a Consultant in Emergency Medicine at St. Vincent's University Hospital and clinical lead of Emergency Medical Science at University College Dublin. He is also medical director of the Wicklow Cardiac First Responders Group.

\section{Mr. Michael Nolan MA DipEd CCP(f)}

Michael has served as a paramedic, Critical Care Flight Paramedic, Professor, Deputy Chief of the Ottawa Paramedic Service, Director of Emergency Management for the City of Ottawa, President of the Paramedic Chiefs of Canada and Chairman of KidActive, a not for profit organization in support of healthy childhood development. Currently, Michael is the Paramedic Service Chief and Director of Emergency Services for the County of Renfrew, in Ontario,
Canada. Since working as a front line clinician, Chief Nolan has worked to align and advance emergency services leadership locally, nationally and internationally through research, government relations, policy development and the creation of regulatory standards in support of evidence based practice for paramedicine and emergency services.

\section{Mr. Cian O'Brien BSc(Hons.) MPH RGN EMT}

Cian works in the Emergency Management Office with the Health Service Executive South Region, Cork, Ireland. From a clinical perspective, Cian is an Emergency Medical Technician, Registered General Nurse, and holds a Masters degree in Public Health \& Epidemiology from University College Cork. A life-long member of St. John Ambulance Brigade, Cian has always had a keen interest in pre-hospital emergency care. He currently holds posts at both local and national levels. Cian is the National Director of the Emergency First Responder Programme, and the Programme Director for the Emergency Medical Technician Programme in the southern region of Ireland.

\section{Professor Peter O'Meara BHA MPP PhD FPA FANZCP}

Peter is an internationally recognised expert on paramedicine models of care and education. He was one of the first paramedics in the world to complete a doctoral qualification researching paramedicine. He is the inaugural Chair of Rural and Regional Paramedicine in the LaTrobe Rural Health School, Bendigo. He has published one book, nine book chapters, 59 peer-reviewed papers and 13 other publications.

\section{Professor Tom Quinn MPhil RN FRCN FESC FAHA}

Tom is Professor of Nursing at Kingston University and St George's, University of London. He has worked in acute cardiovascular care for over 30 years in various clinical, research and strategic roles in hospitals, the ambulance service, the Department of Health and latterly as a full time academic. While at the Department of Health, where he was closely involved in the National Service Framework for Coronary Heart Disease, and helped to establish the Defibrillators in Public Places Initiative, he was an ex officio member of the Resuscitation Council (UK) Executive, and for many years a member of the Joint Royal Colleges Ambulance Liaison Committee (JRCALC). He is a member of the Community Resuscitation Committee established jointly by the BHF, Resuscitation Council (UK), Association of Ambulance Chief Executives and NHS England as part of the Cardiovascular Outcomes Strategy. He is a member of the PARAMEDIC and PARAMEDIC-2 Trialists' group.

\section{Dr. Damien Ryan MB BCh BAO BMedSci MRCSI DipIMC(RCSEd) FRCSEd FRCEM}

Damien is a Consultant in Emergency Medicine at University Hospital Limerick and Director of the Centre for Prehospital Research at the University of Limerick. He is also medical director for Lifeline Ambulance Service. He previously completed a fellowship in prehospital and transport medicine 
at the University of Toronto. He has published and presented on prehospital and emergency medicine research both nationally and internationally and continues to be involved in paramedic education and professional development.

\section{Ms. Brigid Sinnott RGN MScEMS}

Brigid qualified as an RGN in 1989 from Waterford University Hospital. She worked in Wexford General Hospital from 1990 until 2006. Fourteen of those years were spent in Intensive Care. In 2006 Brigid took up the role of the Basic Life support Coordinator in the Irish Heart Foundation, she continues in this role today ten years on. In 2012 she completed her MSc in Emergency Medical Science (Immediate Care) in UCD. Her current role involves her strengthening all the links in the chain of survival, mainly through training. She is passionate about the need to improve the quality of CPR in Ireland.

\section{Ms. Nadine Seymour NDipEMC BTech MPhil}

Nadine is an advanced life-support paramedic working at the Namibia University of Science and Technology (NUST). She started her ambulance career in 2001 as a Basic Ambulance Assistant and in 2003 completed the Ambulance Emergency Assistant course. She then joined the Western Cape Provincial Government Emergency Services and during this time completed the National Diploma in Emergency Medical Care as well as the Bachelors degree in Emergency Medical Care at Cape Peninsula University of Science and Technology. She completed a Master of Philosophy in Emergency Medicine specialising in Clinical Emergency Care at the University of Cape Town, during which time she completed electives in Education as well as Disaster management. She is currently Head of Department for Health Sciences at NUST which incorporates four programmes namely Biomedical Sciences, Environmental Health Sciences, Emergency Medical Care as well as Health Information Systems Management.

\section{Dr. Marietjie Slabbert MB ChB MSc(Critical Care) DipIMC(RCSEd) DipRTM(RCSEd) FFICM FRCA}

MJ graduated from medical school in South Africa in 2001. She worked in Cape Town for three years in Emergency Medicine and Pediatric Trauma, and also worked briefly with Red Cross Air Mercy Services. After a brief stint as an Emergency Medicine resident in the UK, she started her Anesthesiology and Critical Care Medicine joint residency training in 2005. She also completed 18-months full-time Helicopter Emergency Medicine (HEMS) and Retrieval Medicine training with Careflight and the Royal Flying Doctors Service in Australia, London's Air Ambulance and Essex and Hertfordshire Air Ambulances in the UK. Since 2008, she has been flying with Thames Valley Air Ambulance in Oxford, England, in her role as a Pre Hospital Emergency Physician. She is currently completing a Fellowship in Trauma and Critical Care Anesthesiology and Trauma Team Leading in Toronto, Canada, and has done some work with Ornge (the Ontario Air Ambulance Service) in 2015. She will be taking up an Attending Physician (Consultant) post in Critical Care and Anesthesiology in British Columbia, Canada from August 2016 onwards.

\section{Dr. Christine Tomkinson BM BS BSc(Hons.)}

Christine completed a Bachelor of Science degree in Biological Sciences (with a minor in neuroscience) from the University of Guelph in Ontario, and graduated with Bachelor of Medicine and Bachelor of Surgery degrees from the University of Limerick, Ireland. She has taught assessment and management of neurological emergencies and neurological conditions to civilian and remote paramedics and medical students in Ireland, Canada, the Middle East and the USA. She is currently a Resident Physician in Adult Neurology in Ontario, Canada.

\section{Professor Paresh Wankhade BSc MA MPA PhD FRSA FHEA PGCert.}

Paresh is the Professor of Leadership and Management at Edge Hill University Business School, UK. He has a PhD in ambulance performance \& culture change management from the University of Liverpool with expertise in the field of emergency services management. He is also the Editor-InChief of International Journal of Emergency Services . He serves as the lead of the Strategic Advisory Board of the Larrey Society, an international think tank on hospital care and ambulance delivery. His published work has focussed on the analyses of strategic leadership, organisational culture, organisational change and interoperability within different emergency services settings. His recent work (co-authored with professionals) has explored leadership and management perspectives in the ambulance and police services.

Mr. James Ward RGN BSc(Hons.) GradDipEMS AP James is an Advanced Paramedic with the National Ambulance Service. James is a former Emergency Nurse, who previously worked and studied in Ireland and the United Kingdom. Areas of interests include expanding paramedic roles, performance and quality improvement and alternative pathways for patient care.

Source of support/funding: None.

Conflict of interest: Not applicable

Provenance and review: Commissioned, not peerreviewed.

This is an Open Access article distributed under the terms of the Creative Commons Attribution-Non-Commercial-ShareAlike 4.0 International (http:// creativecommons.org/licenses/by-nc-sa/4.0/), which permits use, distribution, and reproduction in any medium, provided the original work and any attributes thereof are properly cited, are distributed under the same licence, and that the work is not used for commercial purposes. 